\title{
PULSATILE DRUG DELIVERY SYSTEMS: PULSINCAP SYSTEM
}

\author{
Tarun Garg*, Arsh Chanana, Ankit Gupta, Neetu Khatri, Govind Sharma \\ Department of Pharmaceutics, Seth G. L. Bihani S.D. College of Technical Education, Sriganganagar.
}

\section{INTRODUCTION}

Pulsatile systems are achieving a lot of interest as they deliver the drug at the right site of action at the right time and in the right amount, thus providing spatial and temporal delivery and increasing patient compliance. These systems are designed based on the circadian rhythm of the body. The principle rationale for the use of pulsatile release is for the drugs where a constant drug release, i.e., a zero-order release is not desired. Products available as once-a-daily formulation based on Pulsatile release like Pulsincap ${ }^{\circledR}$, Ritalin ${ }^{\circledR}$, and Pulsys ${ }^{\circledR}$. In these systems, a most important and widely used pulsincap system is described here.

\section{PULSINCAP SYSTEM}

R. R. Scherer (International Corporation, Michigan, US) developed Pulsincap. This system comprises of a water-insoluble capsule enclosing the drug reservoir. Seal the drug contents into the capsule body, a swell able hydrogel plug was used. It swelled, when this capsule came in contact with the dissolution fluid and after a lag time, the plug pushed itself outside the capsule and rapidly released the drug (Fig. 1).

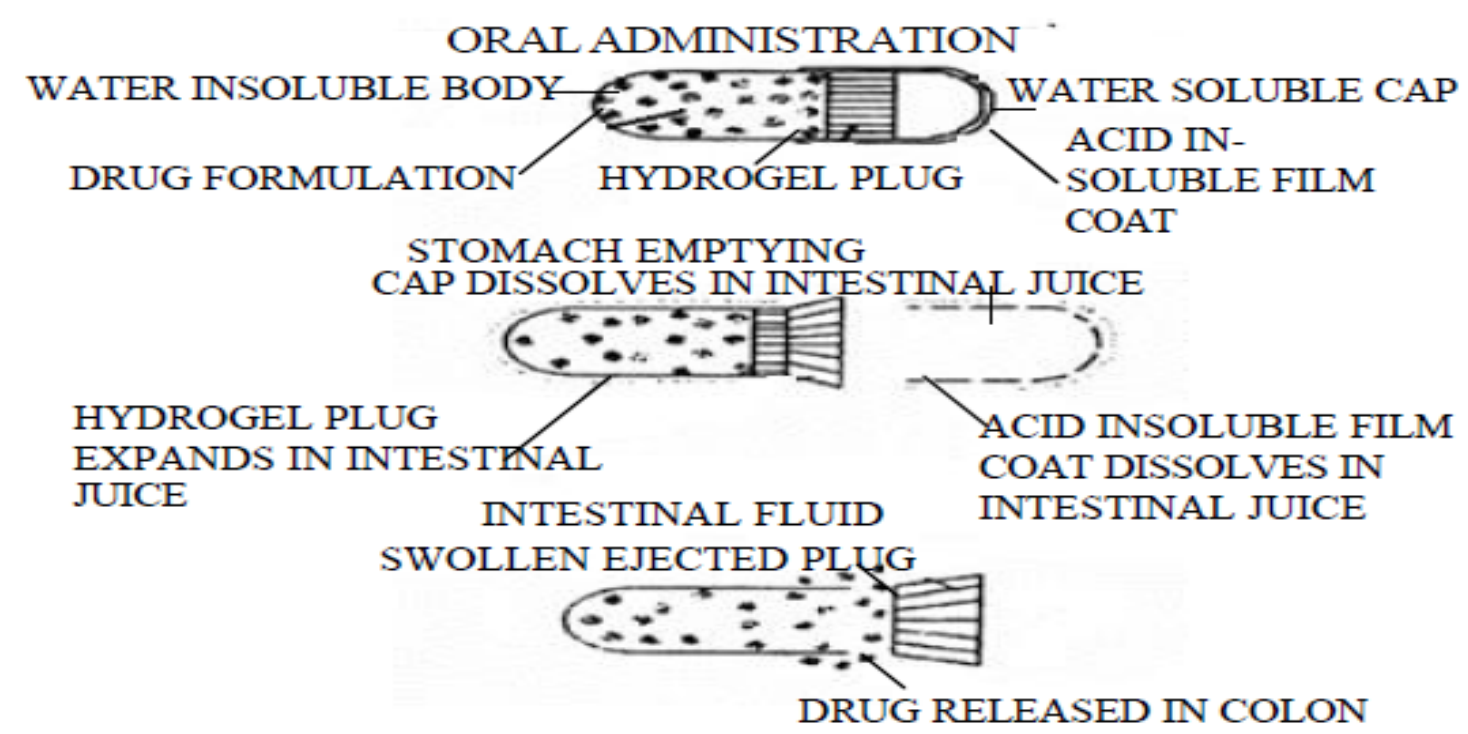

Fig. 1. Design of Pulsincap System

A various polymers used for designing of the hydrogel plug were various viscosity grades of hydroxyl propyl methyl cellulose, polymethyl methacrylates, poly vinyl acetate and poly ethylene oxide. The length of the plug and its point of insertion into the capsule controlled the lag time. Pulsincap was studied in human volunteers and was reported to be well tolerated. As the swelling hydrogel polymer plug replaced the erodible tablet, the dependence of the dimensional accuracy between the plug and the capsule for the pulling mechanism of the plug from the capsule was also overcome. A release profile is characterized by a period during which no release followed by rapid and complete drug release. Release using this system was found to be reproducible in-vitro and in-vivo. When gastrointestinal transit of the formulations was carried out by gamma scintigraphy, it was found that in six of the eight subjects that the device reached the colon before drug was released. The formulation had been administered with the subjects in a fasting state. Effects of food and gastric retention time were not investigated. In later scintigraphic studies, it was found that the site of release of drug in the gastrointestinal tract varied. In one subject, the formulation even remained in the stomach for a long time and drug was also released in the stomach. Ross et. al. used low substituted hydroxylpropyl cellulose for the expulsion system for the release of propanolol over a time period of 2-10 hr. This could be controlled using compressed erodible tablets made of lactose and HPMC. Krogel and Bodmeier studied the release of Chlorpheniramine utilizing the erodible plugs ${ }^{1,2}$. 


\section{CONCLUSIONS}

There is a constant need for new delivery systems that can provide increased therapeutic benefits to the patients. Pulsatile drug delivery is one such system (pulsincap) that, by delivering drug at the right time, right place, and in right amounts, holds good promises of benefit to the patients suffering from chronic problems like arthritis, asthma, hypertension, etc.

\section{REFERENCES}

1. M. Kumar, Platform technologies for colon targeted drug delivery system: A Review Article, Journal of Pharmacy Research, 3(3), 2010, 543-547.

2. S. Arora, Pulsatile drug delivery systems: An approach for controlled drug delivery, Indian journal of Pharmaceutical Sciences, 68, 2006, 295-300. 